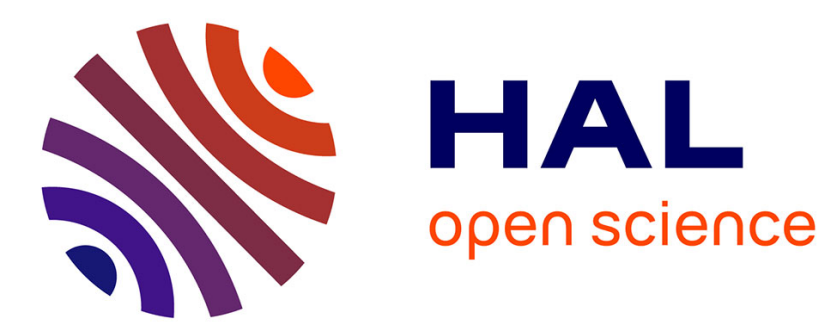

\title{
Exploitation scenarios in industrial system LCA
}

François Cluzel, Bernard Yannou, Dominique Millet, Yann Leroy

\section{To cite this version:}

François Cluzel, Bernard Yannou, Dominique Millet, Yann Leroy. Exploitation scenarios in industrial system LCA. International Journal of Life Cycle Assessment, 2014, 19 (1), pp 231-245. 10.1007/s11367-013-0631-z . hal-00850483

\section{HAL Id: hal-00850483 https://hal.science/hal-00850483}

Submitted on 6 Aug 2014

HAL is a multi-disciplinary open access archive for the deposit and dissemination of scientific research documents, whether they are published or not. The documents may come from teaching and research institutions in France or abroad, or from public or private research centers.
L'archive ouverte pluridisciplinaire HAL, est destinée au dépôt et à la diffusion de documents scientifiques de niveau recherche, publiés ou non, émanant des établissements d'enseignement et de recherche français ou étrangers, des laboratoires publics ou privés. 
The final publication is available at link.springer.com: 10.1007/s11367-013-0631-z

\title{
Exploitation scenarios in industrial system LCA
}

\author{
François Cluzel $^{1}$, Bernard Yannou ${ }^{1}$, Dominique Millet ${ }^{2}$, Yann Leroy $^{1}$ \\ ${ }^{1}$ Laboratoire Genie Industriel, Ecole Centrale Paris \\ Grande Voie des Vignes, 92290 Chatenay-Malabry, France \\ Phone: +33 (0)141131328 \\ Fax: $+33(0) 141131272$ \\ Email: francois.cluzel@ecp.fr \\ ${ }^{2}$ LISMMA, Supméca Toulon \\ Quartier Mayol, Maison des Technologies, 83000 Toulon, France
}

\begin{abstract}
Purpose: This paper considers the variabilities that exist in the exploitation of a complex industrial system. Our scenario-based LCA model ensures the reliability of results in situations where the system life cycle is very uncertain, where there is substantial lack of data and/or where time and resources available are limited. It is also an effective tool to generate exploitation recommendations for clients.
\end{abstract}

Method: Existing quantitative uncertainty methods in LCA require a huge amount of accurate data. These data are rarely available in simplified and upstream LCA for complex industrial systems. A scenario-based approach is the best compromise between acceptable quality of results and resources required. However, such methods have not yet been proposed to improve the environmental knowledge of the system in the case of exploitation scenarios. The method proposed here considers a limited number of scenarios (3 or 4 ) that are defined using the Stanford Research Institute (SRI) matrix. Using results from past projects, relevant parts of the system are listed, and expert knowledge and parameters are associated with these parts and quantified. A classical LCA process then provides the results for the different scenarios.

Results and discussion: The method was applied to an Alstom Grid AC/DC conversion substation for the primary aluminium industry. A previous study had limited scope, as the life cycle was poorly understood. Relevant parts were thus clearly identified: spare parts program, transport failures, preventive and corrective maintenance, updates and revampings, lifetime modulation and end-of-life. Four scenarios were considered: best case, worst case, baseline (expected future) and a highly different alternative. Results show the pertinence of considering several exploitation scenarios when the life 
cycle is not predictable, as the environmental impacts may vary widely from one case to another. A sensitivity analysis also shows that some relevant parts such as updates and revampings will need to be carefully considered in futures studies.

Conclusions: The consideration of three exploitation scenarios (best case, baseline and worst case) appears to be extremely pertinent when considering simplified LCA of industrial systems with high uncertainties and limited time and resources. This model is also very useful to generate good practice and recommendations towards clients, thus initiating a dialog centred on eco-design and continuous improvement.

Keywords: Life Cycle Assessment, Life Cycle Inventory, complex industrial system, scenario-based LCA, exploitation scenario.

\section{Introduction}

In recent decades, Life Cycle Assessment (LCA) has become an essential tool for performing ecodesign (i.e. the integration of environmental aspects into product design and development, with the aim of reducing adverse environmental impacts throughout a product's life cycle (ISO 14006:2011)) in companies. Indeed this normalised methodology (ISO14040:2006, ISO14044:2006) is said to be the most effective quantitative environmental assessment tool (Millet et al., 2007) as it delivers the most accurate results (Dewulf, 2003). The identification of the most environmentally impacting elements of a products system life cycle generates eco-innovation insights to develop new products (Finnveden and Ekvall, 1998). However, the results of such a process clearly require a large amount of high quality data (Reap et al. 2008a, 2008b), and LCA is thus undeniably a time- and resource-consuming activity (Hur et al., 2005; Weckenmann and Schwan, 2001). Even if eco-design is generally expected and supported by the top management of companies, it is often awkward to obtain complete data and the necessary allocation of human resources for satisfactory analysis. Consequently, life cycle scenarios of complex industrial systems are not sufficiently thought through or modelled, being at best an aggregate of factors. This also results in decorrelated life scenarios (along lifetime) and, ultimately, to non representative environmental impact profiles of real life.

\subsection{Specificities of complex industrial systems in LCA}

This opposition between the quality of LCA results and available resources is amplified in companies supplying complex technical and organizational industrial systems such as factories. Here, complexity 
induces major issues in terms of modelling, prediction or configuration. In the systems engineering domain, Blanchard and Fabricky (2011) characterise engineered systems as systems that achieve operational objectives; that operate over a complete life cycle; that are composed of a combination of resources (humans, materials, equipment, money, etc); that are composed of subsystems and components that interact with each other; and that are influenced by external factors from larger systems and in interaction with the natural world. Adding an environmental dimension, we define a complex industrial system in the sense of eco-design as:

- A large-scale system in terms of subsystems and components, mass and resource usage;

- A system whose life cycle is difficult to predict at the design level in the long-term, in particular its lifetime, updates, maintenance and end-of-life;

- A system whose subsystems may have different life cycles and different obsolescence times;

- A system which is in close interaction with its environment (super system, geographic site etc);

- A system supervised by human decisions and management.

But LCA is more convenient for relatively simple products than for complex systems (Millet et al., 2007). The application of LCA for such systems highlights particular needs not only in terms of time and resources, but also in terms of technical aspects such as goal and scope definition or data inventory. Thus, organizing the eco-design of complex industrial systems requires the conventional LCA process to be adapted. For instance, lean principles can be applied, as shown in (Cluzel et al., 2012). For this adapted eco-design approach to complex industrial systems, a first LCA is performed for a reference system and its corresponding environment. But difficulties quickly appear because there is currently no clear method to analyse impacts at different levels of complexity. This is why before being able to communicate LCA results (through product environmental profiles for example) that would lead to long term work, the first strategic step consists in identifying the potential environmental impacts, at a high level and in the most reliable way. Consequently, the primary need is to use the first system assessment to build a list of eco-innovative improvement projects that can feed the R\&D program of the coming years.

Considering LCA for these types of system, the major issue concerns the availability and the quality of the system life cycle data (Cluzel et al., 2012). Indeed in many complex system industries, the use phase and the end-of-life phase only depend on the clients (i.e. the users of the system), and data are 
awkward to obtain where no client relationship management system exists. The Alstom Grid AC/DC conversion substations, for example (see Section 4), are characterized by their long life (more than 30 or 40 years) or their uniqueness (each substation is customized to comply with a tender from aluminium producers). Companies now consider that the realization of one specific LCA for each system design would require too much time and resources. However, the environmental impacts of a factory such as an electrical substation may differ markedly from one geographical site to another due, for example, to the electrical mix or the client management in terms of maintenance or updates. We include these issues in the more global notion of "industrial system exploitation".

\subsection{Considering exploitation uncertainties}

It is thus necessary to define a compromise between the simplification of the LCA model, the scientific validity of the results and the commercial use in answering specific tenders from clients. Actually an over-simplified model would probably limit both the effectiveness of the results for a given system and the ability to meet clients' requirements. On the contrary, a very accurate model applied to complex industrial systems would not be easily appropriable by a company as it would need too much time and resources. Great accuracy is not necessary at an upstream level, where the objectives consist in defining first improvement directions (Leroy and Froelich, 2010).

The ideal model would combine LCA, giving a high level global view of the product family, with the ability to customize studies for each specific project, thus taking into account uncertainties and system life cycle variables. The notion of scenario really fits this need to represent complex life cycles and to take into account the numerous associated factors in a simplified LCA approach. That is why it is preferred in this study to more mathematical uncertainty models (see for example (Huijbregts, 1998)) that we consider too complex and poorly applicable (Ross et al., 2002). Indeed these methods offer accurate uncertainty data, and thus better decision support, but they require additional efforts (Ciroth, 2003). Concerning Monte Carlo methods in particular, Huijbregts et al. describe the specification of uncertainty distributions as "a very difficult and time-consuming exercise [...] for the enormous amount of parameters involved in the inventory analysis” (Huijbregts et al., 2001).

Two main objectives are targeted in the scenario-based model. The first one is to give more credence to the LCA results of complex industrial systems in order to generate appropriate eco-innovative R\&D projects. The second one is to initiate productive discussions with clients, thus generating exploitation recommendations. 
Section 2 considers scenario development techniques and their application into the LCA field. This literature review allows us to choose an adapted technique and propose a methodology to consider exploitation scenarios in LCA. This methodology is detailed in section 3 and applied in section 4 to an Alstom Grid AC/DC conversion substation for the aluminium industry. Finally, some concluding remarks and perspectives are proposed in section 5.

\section{Scenario development and use in LCA}

\subsection{Scenario definition and categorization}

The notion of scenario in model-based approaches has received numerous definitions in the literature. Pesonen et al. (2000) give an overview of some of these definitions, including three basic elements: definition of alternative future circumstances, path from the present to the future, and inclusion of uncertainty about the future.

In the same paper, which synthesizes the works of a SETAC working group on scenario development in LCA, the following definition is chosen: “A description of a possible future situation relevant for specific LCA applications, based on specific assumptions about the future, and (when relevant) also including the presentation of the development from the present to the future." We adopt this definition in this paper.

Different scenario types may be considered in prospective studies. A categorization of scenarios is proposed by Börjeson et al. (2006). This categorization distinguishes 3 main scenario categories, divided into 6 subcategories:

- $\quad$ Predictive scenarios answer the question What will happen? Predictive scenario types are forecast (the likely scenario occurs) and what-if (conditioned to some specific events).

- Explorative scenarios answer the question What can happen? Explorative scenario types are external (considering external (exogenous) factors) and strategic (conditioned to some actions completed in a certain way).

- Normative scenarios answer the question How can a specific target be reached? Normative scenario types are preserving (adjustments to current situation) and transforming (the prevailing structure blocks necessary changes).

Earlier studies consider different scenario types, or rather different designations that could describe the same types. For example, Fukushima and Hirao (2002) consider forecasting and backcasting scenarios, 
while Pesonen et al. (2000) take what-if and cornerstone scenarios into account by considering time and complexity. What-if scenarios concern simple objects and short term studies, while cornerstone scenarios are more suited for complex objects and long term approaches.

A CALCAS report (Zamagni et al., 2008) states that these scenario types are included in Börjeson's scenario categorization. Concerning the two different scenarios considered by Pesonen et al. (2000) and Weidema et al. (2004), it estimates that what-if scenarios belong logically to the predictive scenarios of Börjeson's categorization, while the cornerstone scenarios belong to Börjeson's explorative scenarios (Zamagni et al., 2008).

\subsection{Scenario development techniques}

Börjeson et al. distinguish three main steps to generate a set of scenarios (Börjeson et al., 2006):

- Generate ideas and knowledge about some parts of the future;

- Integrate them into scenarios;

- $\quad$ Check the consistency of the scenarios.

Particular methods are used to perform these different steps. Scenario development techniques (covering the second step) enable the construction and use of a set of scenarios. Bishop et al. (2007) give an overview of numerous techniques, classified into eight categories:

1. Judgment: based on the judgment of individuals describing the future.

2. Baseline/expected: produces only one scenario, which could be the base for alternative scenarios (generated with other techniques).

3. Elaboration of fixed scenarios: based on simple tools to generate a predefined number of scenarios.

4. Event sequences: based on probability trees.

5. Backcasting: based on a desirable future and the identification of the way to reach it.

6. Dimensions of uncertainty: based on the identification of specific sources of uncertainty.

7. Cross-impact analysis: based on probability matrices and the calculation of conditional probabilities.

8. Modelling: based on simulations and the variation of the inputs or the structure of the model. Another interesting method is Formative Scenario Analysis (FSA), detailed by Tietje (2005). The method consists in identifying a small and reliable set of consistent scenarios with mathematical tools such as consistency analysis. It is a powerful method but it clearly needs accurate quantified data. 
However these techniques concern scenario development in general. The next subsection particularly focuses on scenarios in Life Cycle Assessment.

\subsection{Scenarios in LCA}

Annex 2 of the CALCAS report D7 (Zamagni et al., 2008), concerning current research needs and limitations in LCA, gives a precise literature review of the use of scenarios in Life Cycle Assessment. The definition of the set of scenarios is performed in the goal and scope stage (ISO14040:2006), while the modelling of scenarios is performed in the LCI and LCIA phases. The results are discussed in the interpretation phase (Zamagni et al., 2008). But scenarios have received little attention in LCA, and two of the main questions raised by (Zamagni et al., 2008) are the following: How should scenarios be defined and categorized? And how should scenarios be developed?

Höjer et al. (2008) consider the use of scenarios for environmental system analysis, including Life Cycle Assessment. The paper focuses on products with a long expected life. In this case external scenarios (in the sense of Börjeson et al. (2006)) are recommended to assess "different options for the foreground system under the influence of different external scenarios".

The working group "Scenario development in LCA" launched by SETAC-Europe (Pesonen et al., 2000; Weidema et al., 2004) focused on two main goals that are to find solutions for problems concerning prospective LCA, and to define a procedure to model uncertain parts of a product system, or parts with different possible alternatives.

They propose a five-step approach (Weidema et al., 2004) that corresponds closely to Börjeson's approach (Börjeson et al., 2006):

1. Identification of the relevant parts of the product systems,

2. Identification of the precision required,

3. Choice of an appropriate method,

4. Scenario development,

5. Consistency check.

Concerning step 3, Weidema et al. highlight the use of extreme scenarios (e.g. a worst case scenario like the Bhopal disaster) (Weidema et al., 2004). They also identify 6 groups of future research methods:

- Extrapolating methods: the future is an extension of the past,

- Exploratory methods focus on structuring possible futures, 
- Dynamic modelling takes mechanisms of past events and causal connections among system elements into account,

- Cornerstone scenario methods : future is essentially unpredictable and several scenarios are helpful,

- Participatory methods use experts to identify one consensual scenario,

- $\quad$ Normative methods identify the scenario leading to one predefined goal.

The number of scenarios to consider is an issue highlighted by Pesonen et al. (2000). A limited number of scenarios (less than four) is recommended, for example one base scenario and two others. Actually if more than four scenarios are proposed, “it becomes unmanageable for most decision makers” (Wack, 1985).

Some other research using scenario-based LCA has also been undertaken. For instance, Spielmann et al. apply Formative Scenario Analysis to prospective LCA of transport systems (Spielmann et al., 2004). They focus on strategic scenarios and the evolution of technologies.

\section{Methodology}

This section will put forward a methodology that meets the requirements expressed in section 1.2.

\subsection{Overview}

The use of scenarios in LCA seems particularly well-adapted to model the exploitation of complex industrial systems. But the objectives of the existing studies we mentioned in section 2.3 do not meet our own objectives. Actually these studies are mainly positioned at a more strategic level (Lloyd and Ries, 2007):

- To compare product alternatives when the future is unpredictable or may follow different trajectories (e.g. with future electrical mixes). This perspective is equivalent to the what-if scenarios.

- To make the best choices in the development of (for example) public policies by minimizing the environmental impacts. This perspective is equivalent to the normative scenarios.

These two perspectives already focus on environmental impact optimisation, whereas in our case the objective is to make the LCA results more reliable because the operational exploitation (in particular the use phase and the end-of-life phase) of the current products is not known precisely enough and may vary from one industrial client to another. These needs concern explorative external scenarios in 
Börjeson's categorization (Börjeson et al., 2006).

This distinction is extremely important as it means that in the present case some data are simply missing, while the other data are uncertain, and no probability distribution is clearly known. Adding to this issue the need for a flexible and easily customizable scenario-based procedure, we propose the following methodological process adapted from (Weidema et al., 2004):

1. Identification of the relevant parts of the product systems: performed through surveys on past projects and meetings with experts in the company or clients.

2. Identification of the level of precision required for results: the results must identify improvement projects at a high level, but as these results will not be communicated externally, a high degree of precision is not necessary.

3. Choice of an appropriate method

4. Scenario development

5. Consistency check

Steps 3, 4 and 5 imply the selection of one particular scenario development technique. Among the 8 categories proposed by Bishop et al. (2007) and shown in section 2.2, only a few seem adapted to our needs. Judgment techniques are considered too opaque and insufficiently formalized. Baseline techniques only include one scenario, which is clearly in contradiction with our needs. Event sequences, dimensions of uncertainty, cross-impact analysis and systems modelling techniques are mainly based on accurate quantified data (probabilities of occurrence for example) that are not available in our case. They are judged too complex and time-consuming to be easily applied to a simplified LCA model. Backcasting techniques concern technology-related prospective analysis and they are thus not pertinent in our case. Finally, elaboration of fixed scenario techniques seem adapted to our needs, as they are easily applicable, they do not require accurate quantified data and they are fully compatible with exploitation scenarios. Two such techniques are proposed by Bishop et al. (2007): Incasting and SRI. The first of these, incasting, creates a set of scenarios using group creativity. It is more oriented towards strategic and surprising scenarios. It does not fully fulfil our needs.

The SRI matrix is a simple tool developed at the Stanford Research Institute in the late 1970s (Hawken et al., 1982). It is particularly adapted to exploitation scenarios based on past projects and fragmented information from clients. That is why this technique is used in this study. It generally considers four scenarios (expected future (called baseline in this paper), worst case, best case, and a highly different 
alternative, i.e. a scenario including surprising or unusual events) (Bishop et al., 2007; Hawken et al., 1982). An illustration of this low number of scenarios is given in Figure 1 and must allow environmental impacts to be framed in time. The highly different alternative is used in the current study to check the robustness of the model.

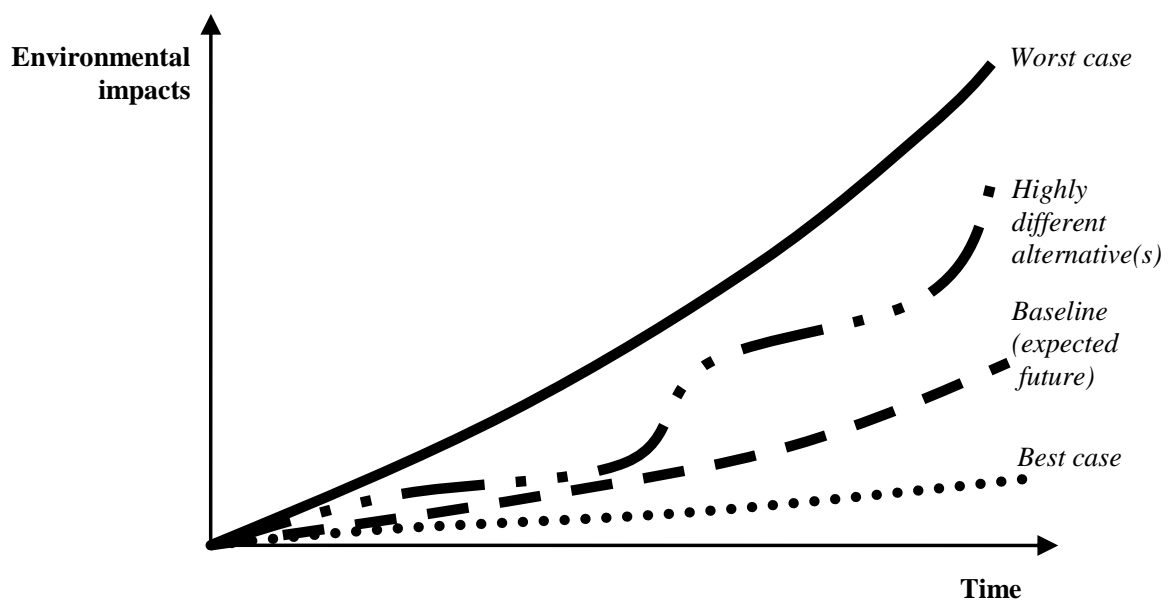

Figure 1. Example of potential environmental impacts generated along four scenarios: best case, baseline, highly different alternative and worst case

Scenarios are listed in columns, while dimensions of the world (i.e. parameters linked to the "relevant parts of the product systems") are recorded in rows (see application in section 3.3). Cells are simply filled out by the SRI matrix users for each scenario and each parameter.

The consistency check is performed manually: the maximum number of scenarios (four, including the best and worst cases) means that it is easy to check if a sufficient range of possible life cycles is being covered. The two next sections give more details about this process.

\subsection{Identification of the parameters}

By studying the life cycle of some Alstom Grid substations (see section 4), different relevant parts of the system life cycle (not necessarily physical parts, but also maintenance operations, lifetimes...) that were not taken into account in the primary LCA have been identified. This process is not new in nature, as it is used in scenario-based approaches or in parameterized LCA (Ostad-Ahmad-Ghorabi and Collado-Ruiz, 2011). However even if these relevant parts are issued from expert knowledge and past project in the company, we consider that they may be reused for numerous applications on complex industrial systems.

The relevant parts of the system may concern all the life cycle phases:

- Spare part programs that may be planned at the design stage, 
- Transport failures may occur en route to the implantation site, leading to the loss of equipments,

- Preventive maintenance operations (periodic servicing to prevent breakdowns),

- Corrective maintenance operations (reparation after breakdowns),

- Updates and revampings (changing or adding of subsystems to improve performance),

- Lifetime extension or shortening, depending on the economic situation, the client choices, or political decisions

- An end-of-life scenario that is often dependent on the implantation country. Transfer options may be included, i.e. the transfer of one healthy subsystem - ordered to stop - to another site to be reused for some years.

For each study, parameters are associated with these relevant parts by company experts. These parameters are the so-called "dimensions of the world", i.e. the rows of the SRI matrix. Some examples of parameters are given later in section 4.2.

\subsection{Scenario development}

The filling out of the SRI matrix allows formalizing the different life cycle scenarios. Examples of such scenarios are given in section 4.2. The best case scenario describes the events that would minimize environmental impact generated throughout system exploitation. The client preserves the equipment and favours a long-term vision. But this does not mean that all the parameters are optimized. For example, there is more preventive maintenance in this scenario than in the worst case, because preventive maintenance minimizes corrective maintenance, which is generally more impacting. The worst case scenario describes the events that maximize the environmental impacts of the exploitation of the system, trying to stay in a realistic perspective. The client favours profitability at all costs and has a short-term vision. The baseline scenario describes what could happen in a "normal" or expected life cycle. It is an intermediary scenario between the worst and the best case. The client follows the supplier recommendations but is not particularly proactive to preserve equipment. Other scenarios may be added to these three base scenarios, but they need to be tailor-made for each study.

Values are then associated to each parameter and for each scenario according to company or client knowledge, expert estimations or hypothesis (depending on the uncertainty of these data).

\subsection{Results valuation}


The LCIA results then provide a set of data that can be used in two perspectives.

The first perspective is internal to the company. It concerns the identification of a portfolio of ecoinnovative $R \& D$ projects. The use of this model ensures that more reliable decisions are made by focusing on environmental issues that are valid with a large number of clients, or in other words for a generic industrial system. This is in particular a powerful tool to guarantee the capability of the system to meet environmental objectives while these impacts largely depend on exogenous parameters. The second perspective is intended for the clients. For the Alstom Grid example it turns out that the substation designers have only few degrees of freedom. Indeed the clients' specifications are very detailed on technical aspects, which limit the ability to radically innovate, as only long-term proven technologies are used. Continuous dialog with the clients is thus necessary to introduce new technologies and make them acceptable, despite the fact that the client would benefit from adopting a more proactive eco-design attitude towards its suppliers. The proposed scenario-based LCA supplies an interesting tool to support this dialog. Indeed the LCIA results may reveal exploitation issues and allow the introduction of good practice, greener technologies and services (concerning maintenance and endof-life for example), or improved strategies (reuse of components for example).

The next section proposes to apply this model to an Alstom Grid conventional substation. We will see below that a poor preventive maintenance program may multiply the environmental impacts by a factor of two.

\section{Application to an Alstom Grid AC/DC conversion substation}

\subsection{General purpose}

Alstom Grid PEM (Power Electronics Massy) designs, assembles and sells substations for the electrolysis of aluminium worldwide. These are electrical stations designed to convert energy from the high voltage network to energy that can be used for aluminium electrolysis, which is a particularly environmentally impacting and energy-consuming activity (Liu and Müller, 2012; Schmidt and Thrane, 2009). An electrolysis substation represents thousands of tons of power electronics components and transformers, costing tens of millions of Euros.

A substation is made up of several groups (four or five in numerous cases) that are composed of a regulating transformer, a rectifier transformer and a rectifier. The groups are connected on the one side to the high voltage network through an electrical substation and on the other side to a busbar that is 
directly connected to the electrolysis potline. All the groups are supervised by control elements that are connected to the electrolysis pots to regulate the process. The amount of energy consumed by a recent primary aluminium plant is comparable to the amount of energy delivered by a nuclear plant unit (greater than $1 \mathrm{GW}$ ). Some details of the flows associated with a substation life cycle are shown in Figure 2 to give an overview of the substation complexity.

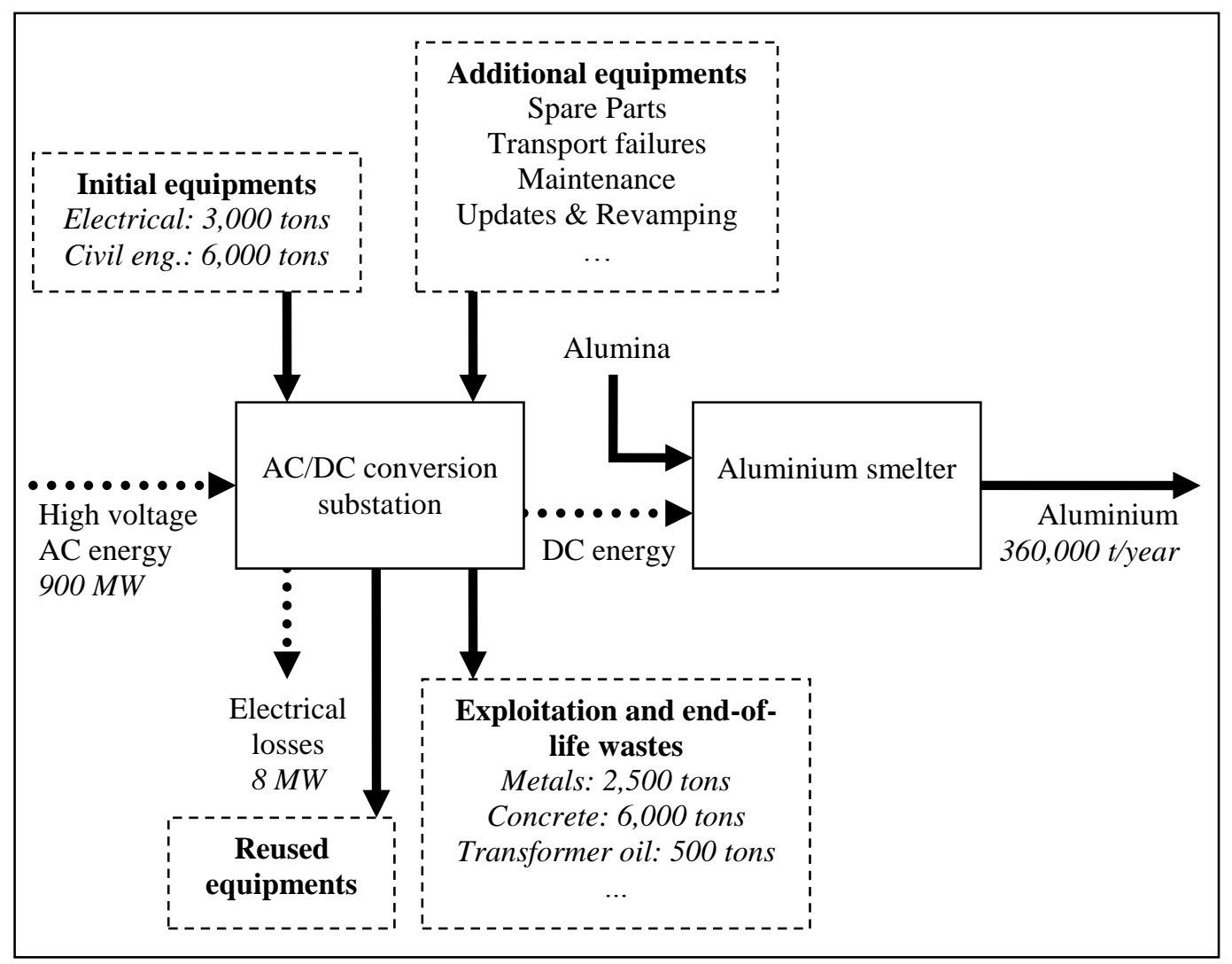

Figure 2. Overview of the flows associated with a substation life cycle. Figures are voluntary rounded off for confidentiality reasons.

The substations are considered to be complex industrial systems for a number of reasons. First, the number of subsystems and components is considerable. For example a substation may include five rectifiers each containing 168 rectifier diodes (i.e. 840 diodes), all of which are large and massive semiconductors consisting of several types of material. Some subsystems could themselves be considered as complex industrial systems (like transformers or rectifiers). Secondly, the lifetime of a substation is long, up to 35 or 40 years. Many uncertainties exist for the use and end-of-life phases. No end-of-life scenario is clearly defined beforehand. In addition, the substation is only a part of the aluminium plant. Their processes are closely connected and interdependent. Finally, no standard design exists: the substation is tailor-made for each industrial client (the primary aluminium producers), even though the 
general design is often the same. It is for these reasons that we consider substations as a product family. In this context, a first LCA was performed on a substation to identify the potential environmental impacts throughout its life cycle, and then to generate improvements (Cluzel et al., 2012).

However the life cycle modelled in this first study was considered as "frozen" as it was not adaptable to a specific case - the use phase, for instance, only considered electrical losses (maintenance, updates and lifetime modulation were not taken into account). Thus the model described in this paper has been applied to the initial study of a conventional substation, in order to make the results more reliable and adaptable to specific projects by taking into account several exploitation scenarios.

\subsection{Goal and scope}

The main objective of the present study is to assess in a reliable way the potential environmental impacts of an AC/DC conversion substation life cycle thanks to different exploitation scenarios. These scenarios allow the customization of the LCA modelling for a specific study. The results also show if the use of scenario is pertinent, and possible benefits for future studies in the company. The selection of adapted scenarios must allow eco-innovative $\mathrm{R} \& \mathrm{D}$ projects to be better lead, and is a valuable tool to provide founded recommendations to clients for the future use and maintenance of their system. Four main life cycle phases are considered, but the application of the model described in this paper has allowed new relevant parts to be added compared to the initial LCA (see (Cluzel et al., 2012)), detailed in Figure 3. The relevant parts are linked to the pre-existing life cycle phases. Some examples of parameters used in the study are associated with each relevant part. The dotted arrows highlight some consequential links between several relevant parts. A large part of the corrective maintenance is for instance determined by the client policy for preventive maintenance.

The study focuses on an Alstom Grid AC/DC conversion substation that has been designed and is currently under construction for the Hindalco Mahan aluminium smelter (India), associated with a captive coal power plant. The following functional unit is chosen: "To provide without interruption the conversion of high voltage energy to energy usable for aluminium electrolysis $\left(360 \mathrm{kA}_{\mathrm{DC}}, 1650 \mathrm{~V}_{\mathrm{DC}}\right)$ according to the Hindalco project specifications, considering the whole system life cycle normalized on one year." This normalized duration (one year) has been chosen to compare alternatives with different life times. 


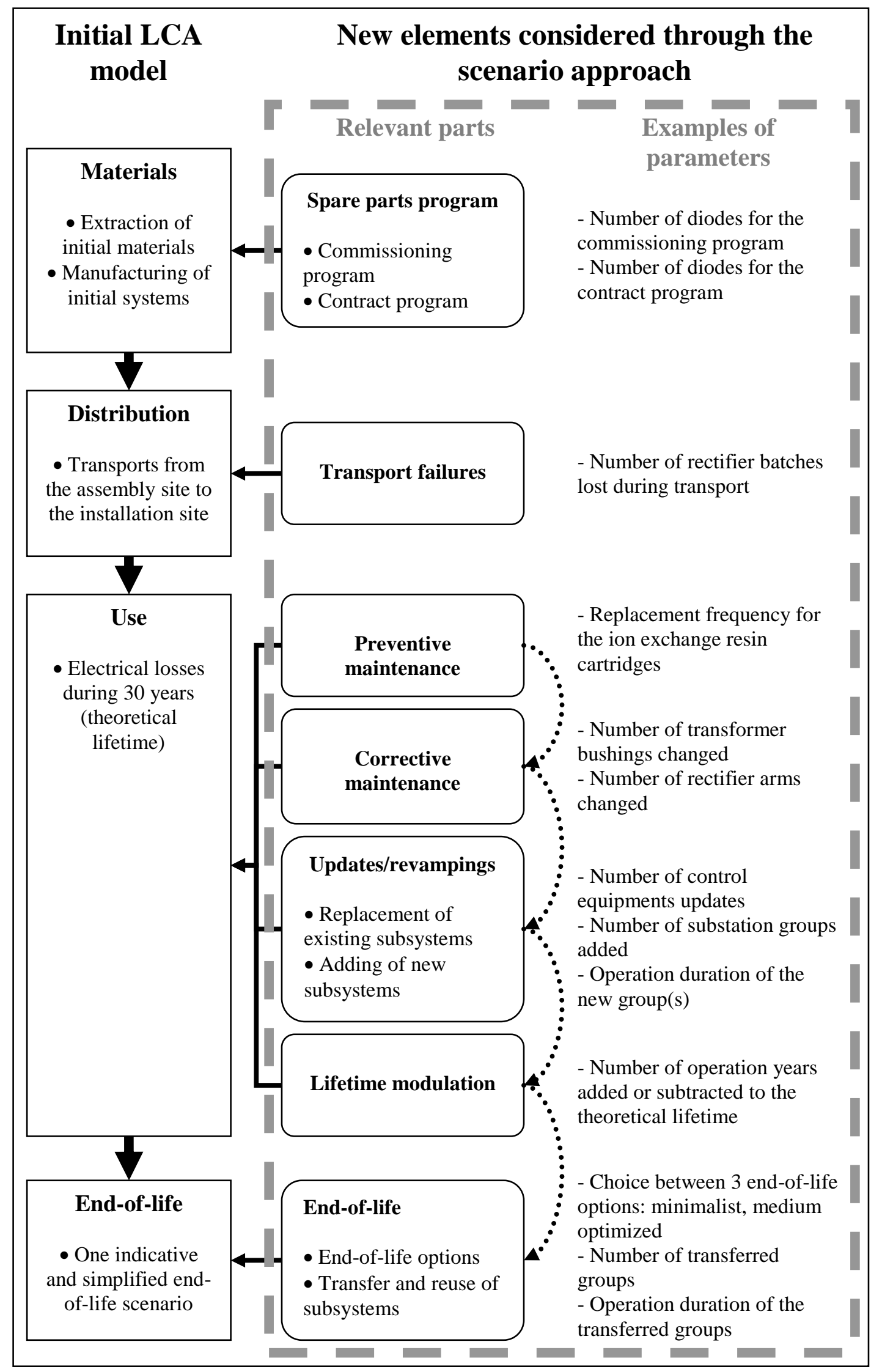

Figure 3. Description of the initial LCA model and the new elements considered through the scenario approach 
Previous results showed that the electrical mix has a strong influence on the one hand on the global substation impacts (as it is an energy system), and on the other hand on the relative contribution of the life cycle phase to global impacts. That is why two different energy supplies are considered in this study: electricity from coal (real Hindalco case) and hydroelectricity (from the regional grid, extrapolated from other smelters).

The system is modelled using SimaPro 7.3 software. Beside the specific data from Alstom Grid, the LCI data come from Ecoinvent V2.1 database (in particular concerning electricity production). The

LCIA results are calculated with the ReCiPe 2008 midpoint $(\mathrm{H})$ V1.03 method.

Table 1. Simplified SRI matrix with three examples of possible scenarios

\begin{tabular}{|c|c|c|c|}
\hline Relevant parts & Best case scenario & Baseline scenario & Worst case scenario \\
\hline Spare parts program & Contractual quantities & Contractual quantities & $\begin{array}{l}\text { Intensified quantities } \\
\text { (more than the } \\
\text { contractual quantities) }\end{array}$ \\
\hline Transport failures & No failure & No failure & Some failures \\
\hline $\begin{array}{l}\text { Preventive } \\
\text { maintenance }\end{array}$ & $\begin{array}{l}\text { Intensified (the client } \\
\text { is very reactive and } \\
\text { exceeds the supplier } \\
\text { recommendations) }\end{array}$ & $\begin{array}{l}\text { Normal (the client } \\
\text { follows the supplier } \\
\text { recommendations) }\end{array}$ & $\begin{array}{l}\text { Neglected (the client } \\
\text { does not follow the } \\
\text { supplier } \\
\text { recommendations) }\end{array}$ \\
\hline $\begin{array}{l}\text { Corrective } \\
\text { maintenance }\end{array}$ & $\begin{array}{l}\text { Minimal (the } \\
\text { preventive } \\
\text { maintenance policy } \\
\text { limits the corrective } \\
\text { maintenance needs) }\end{array}$ & Average & $\begin{array}{l}\text { Intensified (the } \\
\text { neglected preventive } \\
\text { maintenance leads to } \\
\text { more frequent } \\
\text { failures) }\end{array}$ \\
\hline Updates/revampings & $\begin{array}{l}\text { No update (the } \\
\text { equipment is in good } \\
\text { condition and does not } \\
\text { need to be changed. It } \\
\text { fits clients' needs). }\end{array}$ & $\begin{array}{l}\text { Average (some } \\
\text { equipment becomes } \\
\text { obsolete and needs to } \\
\text { be changed). }\end{array}$ & $\begin{array}{l}\text { Intensified (some } \\
\text { equipment is obsolete } \\
\text { and in poor condition. } \\
\text { New equipment is } \\
\text { needed to improve } \\
\text { service quality). }\end{array}$ \\
\hline Lifetime modulation & $\begin{array}{l}\text { Extension of initial } \\
\text { lifetime (as the } \\
\text { equipment is healthy) }\end{array}$ & $\begin{array}{l}\text { No extension or } \\
\text { shortening (the initial } \\
\text { lifetime corresponds } \\
\text { to the reality.) }\end{array}$ & $\begin{array}{l}\text { Shortening of initial } \\
\text { lifetime (some } \\
\text { equipment is in poor } \\
\text { condition, or the } \\
\text { economic situation is } \\
\text { unstable). }\end{array}$ \\
\hline End-of-life & $\begin{array}{l}\text { Optimized (with high } \\
\text { recycling rates) + } \\
\text { transfer of some } \\
\text { subsystems to be used } \\
\text { on another site }\end{array}$ & $\begin{array}{l}\text { Medium (medium } \\
\text { recycling rates) + no } \\
\text { transfer }\end{array}$ & $\begin{array}{l}\text { Minimalist (low } \\
\text { recycling rates) + no } \\
\text { transfer }\end{array}$ \\
\hline
\end{tabular}

Four scenarios were considered in this study: best case, baseline, worst case and marginal. The marginal scenario corresponds to the "highly different alternative" proposed by Bishop et al. (Bishop et al., 2007). In this case, it represents a possible life cycle where the plant is prematurely closed after 10 years of exploitation because of economic reasons, and the substation is reused on another site during 20 years. The main characteristics of the best case, baseline and worst case scenarios are given in Table 
Finally, a last case was considered to control the results of the study. It is called the "initial case", as it corresponds to the "frozen" LCA modelling performed before this study. This case behaves as if no exploitation options have been taken into account (no new relevant parts such as maintenance or lifetime modulation have been added).

The values allocated to each scenario have been identified thanks to past Alstom Grid projects and expert knowledge.

A questionnaire included in an Excel file was used to configure the SRI matrix. Questions are asked to the user to know the quantified values associated to the parameters for a given scenario. This file automatically calculates the value of the parameters that are manually written in Simapro.

\subsection{General results}

The LCIA results are presented in Figure 4 and Figure 5. Considering the eventual transfer cases (best case and marginal scenarios), we considered that the Simapro reuse function is not adapted in our case as it considers that a reused product has the same efficiency as a new product, and all the impacts generated by this subsystem are allocated to the second life cycle (life cycle starting after the transfer). In the best case scenarios for example, 3 groups of the substation are reused for only 2 years, which does not justify this rule as: (1) the reused groups are clearly less efficient than new ones; (2) the main environmental impacts are generated during the first life cycle (before the transfer). We have preferred to manually allocate the materials phase impacts using a pro rata rule, according to the effective number of years of use in the two life cycles. The end-of-life impacts or benefits are allocated to the second life cycle.

Only conclusions resulting from the use of scenarios are proposed in this paper. Other conclusions are presented in more detail in (Cluzel et al., 2012). In order to make the results easy to understand, the LCIA results have been restricted to eight mid-point impact categories that were considered relevant and showing different aspects of the system. 


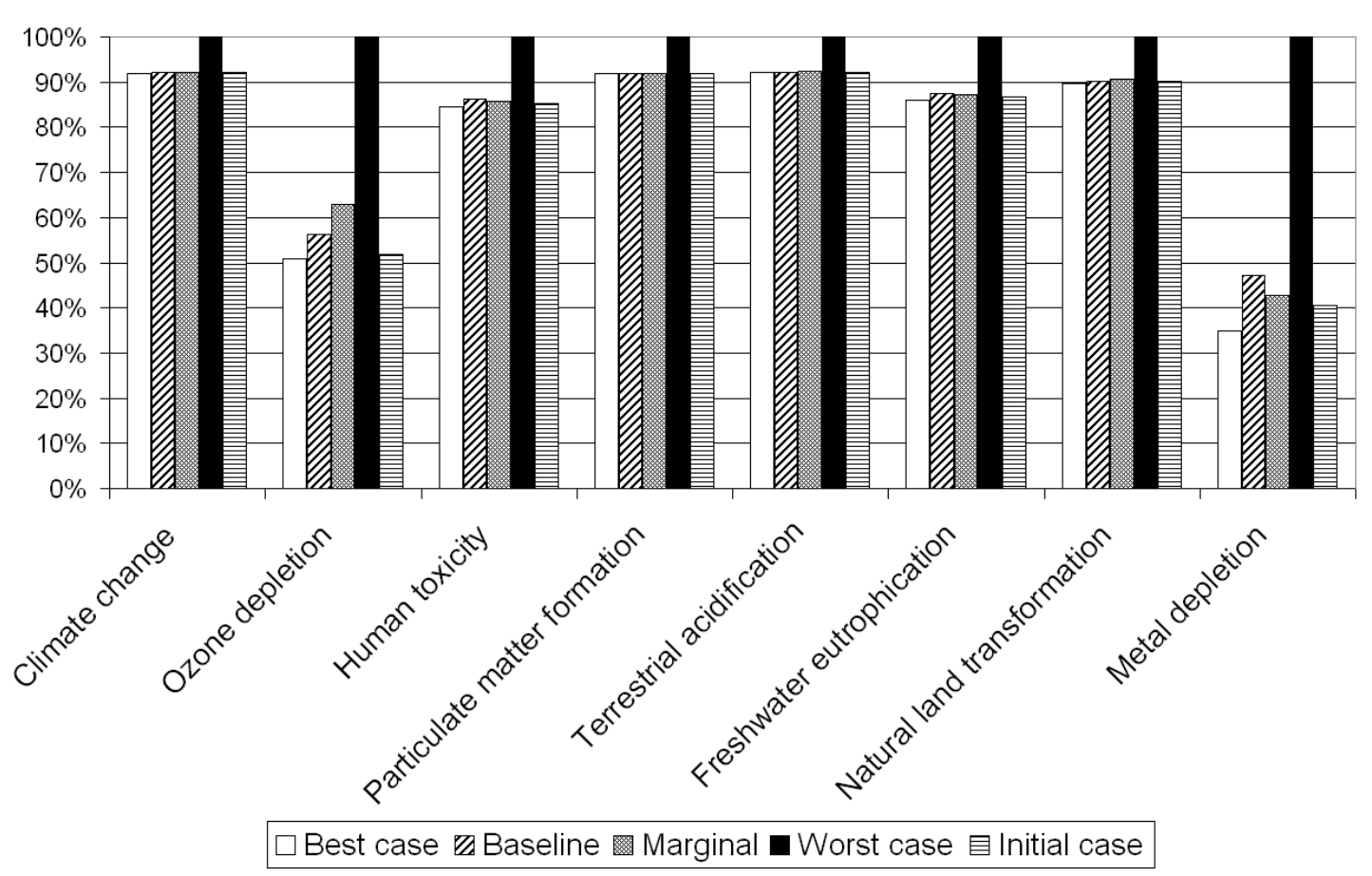

Figure 4. Comparison of the potential environmental impacts of the four scenarios with a coal energy supply

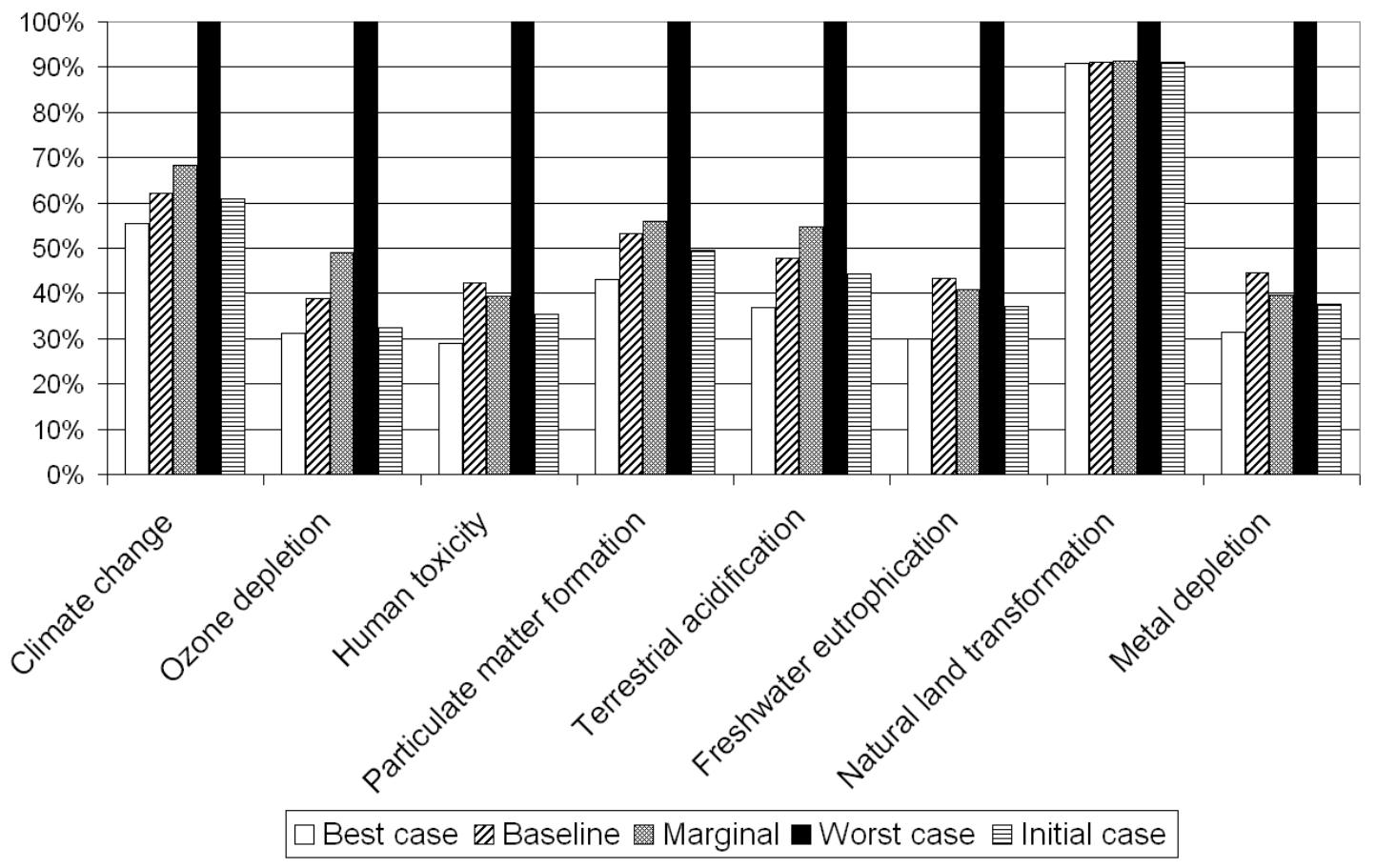

Figure 5. Comparison of the potential environmental impacts of the four scenarios with a hydro energy supply

Figure 4 and Figure 5 compare the potential environmental impacts of the four scenarios in, respectively, a coal and a hydro energy supply. The worst case scenario is chosen as a reference (100\% 
on all impact categories).

In all cases the worst case scenario is logically the one which has the impact on all the impact categories, whereas the best case is always the least impacting. The initial case scenario is always more impacting than the best case, but always less impacting than the baseline scenario. This is also in accordance with what was expected.

However, the gap between the best case and the worst case scenarios, and the relative positioning of the baseline and the marginal scenarios, clearly depends on the energy supply.

For the coal energy supply, the gap between the best case and the worst case scenarios is always inferior to $20 \%$, and the best case, baseline, marginal and initial case scenarios are quite similar, except for two impact categories where the materials phase dominates: ozone depletion and metal depletion. In these categories the best case, baseline and marginal scenarios are not close, and the worst case scenario is much more impacting.

For the hydro energy supply there is a real distinction between all the scenarios, but the best case, the baseline and the marginal scenarios remain within a small range that never exceeds $20 \%$ of the worst case scenario impacts. On the other hand, the gap between this group of scenarios and the worst case scenario is always superior to $32 \%$, except for the impact category natural land transformation. The gap between the baseline and the marginal scenario never exceeds $10 \%$, but neither of the two scenarios is better in all the categories.

Finally this analysis shows that the results of the first LCA performed on this substation (initial case scenario) do not reveal all the potential environmental impacts generated all along the substation life cycle, because some relevant parts have not been taken into account. Moreover the large uncertainty existing on these data shows a large range of possible impacts, in particular with a hydro energy supply, showing a great influence of material aspects. Even if the difference between all the scenarios is not really significant in a coal energy supply for most of the categories, the results on ozone depletion and metal depletion, as well as the results with a hydro energy supply justify in the future the use of several life cycle scenarios to make the decisions based on LCA results more reliable. These results could be refined thanks to an uncertainty analysis. It would consist in measuring uncertainty ranges for the four scenarios in order to determine if the results are significant. However this is not the aim of this paper, whose objective is to introduce the methodology and to propose a first implementation on a real and simplified case study. 
As the marginal scenario reveals itself close to the baseline scenario, we propose to consider in the next study at Alstom Grid three exploitation scenarios: best case, worst case and baseline. But within these scenarios the contribution of each relevant part may differ significantly. These contributions are studied in the next section through a sensitivity analysis.

\subsection{Sensitivity analysis}

The sensitivity analysis proposed in this paper differs from sensitivity analyses generally performed in the LCA field. Here, it aims at identifying which relevant parts need to be carefully model for future implementations of the proposed approach.

The baseline scenario has been chosen as a reference and the sensitivity of the parameters linked to the relevant parts is assessed for the best case and the worst case scenarios. For the relevant parts Spare parts program and Transport failures, the values of the parameters are the same for the baseline and the best case scenarios (see Table 1), so the sensitivity of the parameters linked with the worst case scenario only are considered. The results appear on Tornado diagrams presented in Figure 6 for a coal energy supply and in Figure 7 for a hydro energy supply. The 8 previous impact categories (see Figure 4 and Figure 5) are considered. The relevant parts are presented in order of importance on the majority of the impact categories (this order is not true for some categories, but it is used on all graphs to simplify comparison):

1. Updates/revampings

2. Lifetime modulation

3. End-of-life

4. Transport failures

5. Corrective maintenance

6. Spare parts program

7. Preventive maintenance

With a coal energy supply, two cases may be distinguished. For all the impact categories except ozone depletion and metal depletion, the only significant results are obtained with the relevant part Updates/revampings. Indeed the use phase, and consequently the electrical losses, clearly dominates the environmental impacts, and the only relevant part acting on these losses is Updates/revampings (only in the worst case scenario through the addition of a new group). For the two other impact categories (ozone depletion and metal depletion), material aspects dominate, so the impacts are much 
more modulated by the best case or the worst case scenario. These last results involving material aspects concern all the impact categories with a hydro energy supply, except natural land transformation.

The analysis of these results allows us to draw some conclusions:

- $\quad$ The contribution of the relevant parts Preventive maintenance and Spare parts program is always negligible, so it may not be useful to consider them in future scenarios.

- $\quad$ The major contributor in all cases is the relevant part Updates/revampings (the gap between the best case and the worst case scenarios goes from 7 to $90 \%$ of the baseline scenario impacts).

- $\quad$ The relevant parts Lifetime modulation, End-of-life and Transport failures are also major contributors when material aspects are involved.

- The relevant part Corrective maintenance is only significant on ozone depletion because of the use of PTFE (polytetrafluoroethylene, a technical thermoplastic polymer) in a critical rectifier component. However results concerning ozone depletion need to be carefully considered according to recent research works on the influence of $\mathrm{N}_{2} \mathrm{O}$ on ozone layer depletion. This issue may strongly affect the conclusions (Lane and Lant, 2012).

However this sensitivity analysis does not take into account the correlations between some relevant parts (for example those highlighted in Figure 3). Future work could consider this issue. With this limitation, the current sensitivity analysis allows the scenarios to be refined by focusing on the most significant relevant parts. In this way Spare parts program and Preventive maintenance are not essential, whereas Updates/revampings is indispensable. If more time and resources are allocated to the study, attention needs to be focused on these aspects. This would then become particularly interesting for internal use.

Concerning the external use of these results, the study of the most significant relevant parts such as Updates/revampings or Lifetime modulation may help identify recommendations and good practice for the clients. This particular point is illustrated in the following section. 
Climate change

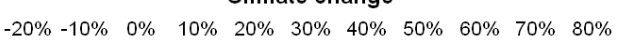

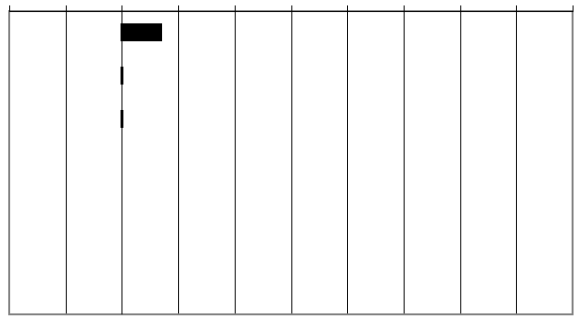

Human toxicity

$\begin{array}{llllllllllll}-20 \% & -10 \% & 0 \% & 10 \% & 20 \% & 30 \% & 40 \% & 50 \% & 60 \% & 70 \% & 80 \%\end{array}$

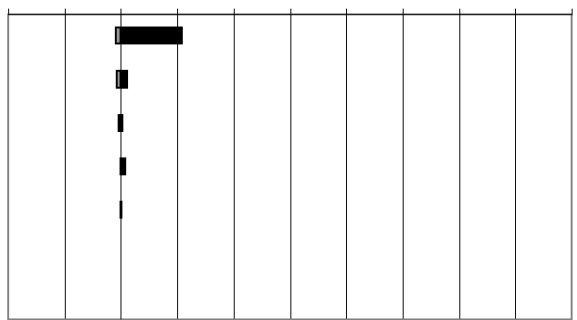

Terrestrial acidification

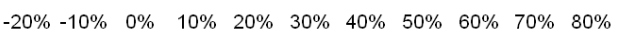

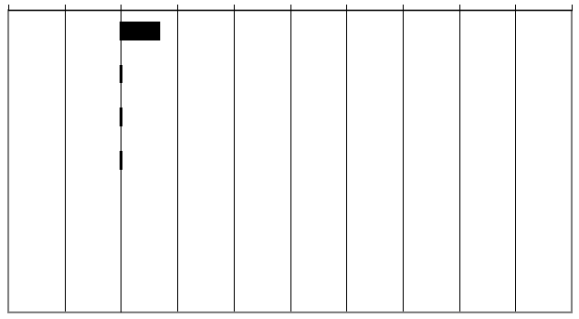

Natural land transformation

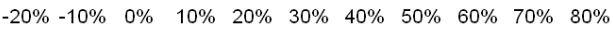

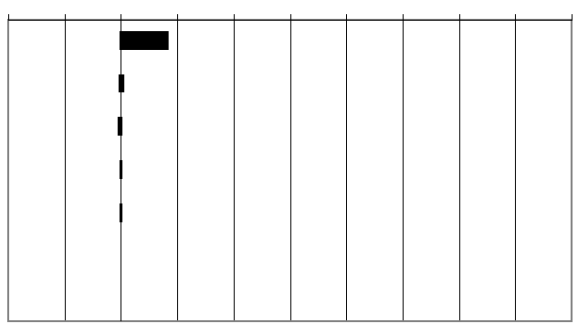

Ozone depletion

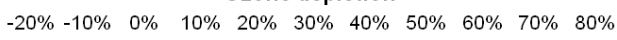

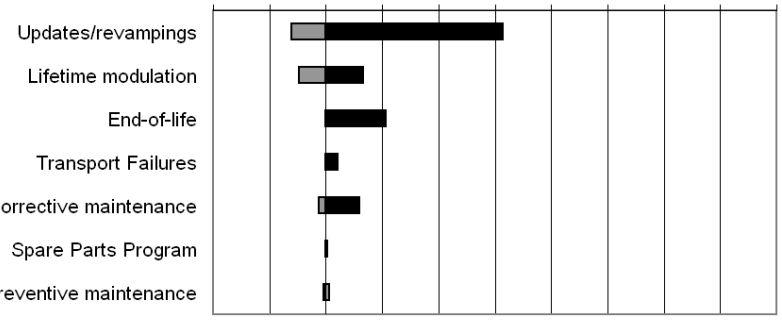

Particulate matter formation

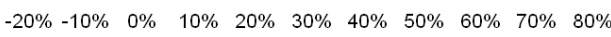

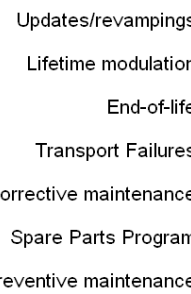

Preventive maintenance

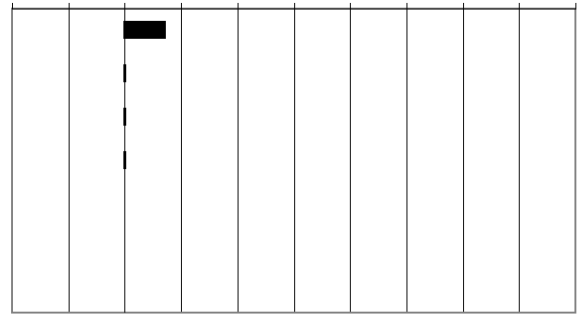

Freshwater eutrophication

$\begin{array}{llllllllllll}-20 \% & -10 \% & 0 \% & 10 \% & 20 \% & 30 \% & 40 \% & 50 \% & 60 \% & 70 \% & 80 \%\end{array}$

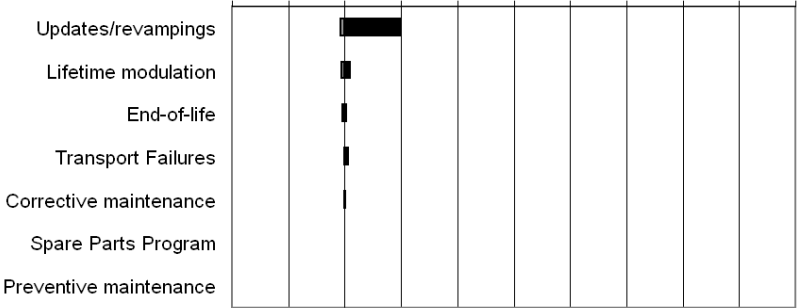

Metal depletion

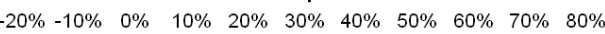

Updates/revampings

Lifetime modulation

End-of-life

Transport Failures

Corrective maintenance

Spare Parts Program

Preventive maintenance

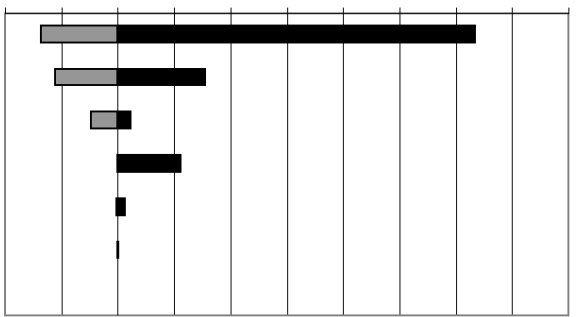

$\square$ Best case $\square$ Worst case

Figure 6. Sensitivity analysis of the relevant parts associated with the best case and worst case scenarios, compared to the baseline scenario taken as a reference and for a coal energy supply. 
Climate change

$\begin{array}{llllllllllll}-20 \% & -10 \% & 0 \% & 10 \% & 20 \% & 30 \% & 40 \% & 50 \% & 60 \% & 70 \% & 80 \%\end{array}$

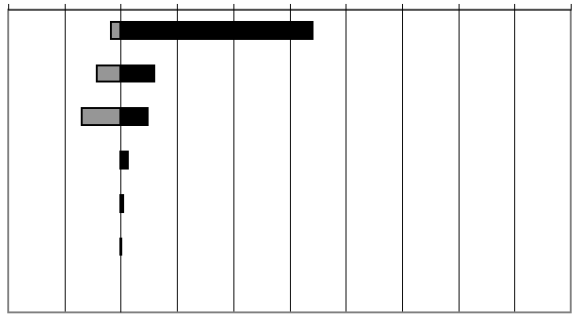

Human toxicity

$\begin{array}{lllllllllll}-20 \% & -10 \% & 0 \% & 10 \% & 20 \% & 30 \% & 40 \% & 50 \% & 60 \% & 70 \% & 80 \%\end{array}$

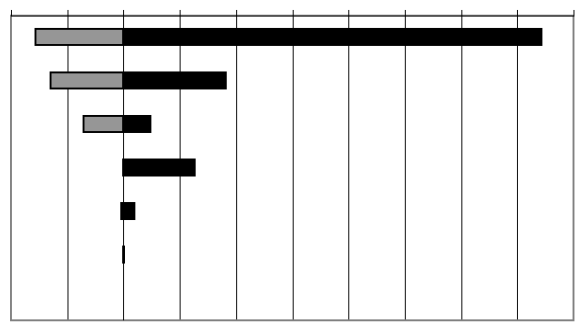

Terrestrial acidification

$\begin{array}{llllllllllll}-20 \% & -10 \% & 0 \% & 10 \% & 20 \% & 30 \% & 40 \% & 50 \% & 60 \% & 70 \% & 80 \%\end{array}$

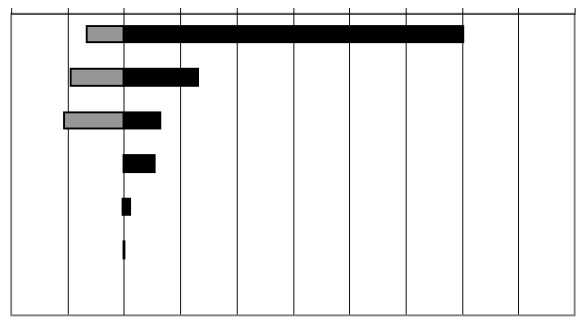

Natural land transformation

$\begin{array}{lllllllllll}-20 \% & -10 \% & 0 \% & 10 \% & 20 \% & 30 \% & 40 \% & 50 \% & 60 \% & 70 \% & 80 \%\end{array}$

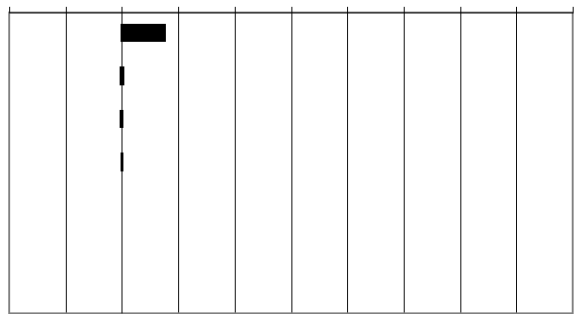

Ozone depletion

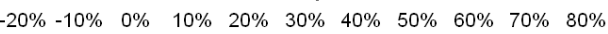

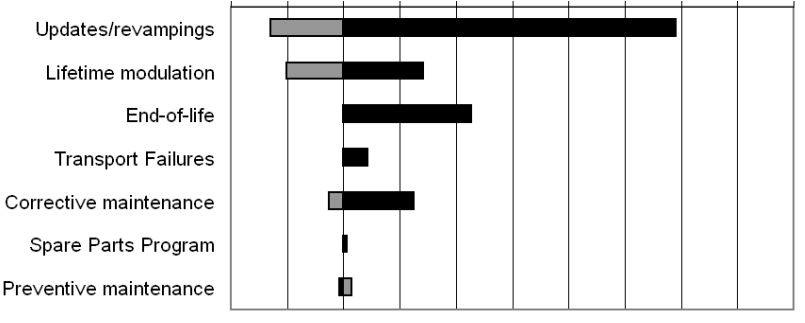

Particulate matter formation

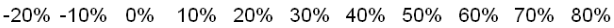

Updates/revampings

Lifetime modulation

End-of-life

Transport Failures

Corrective maintenance

Spare Parts Program

Preventive maintenance

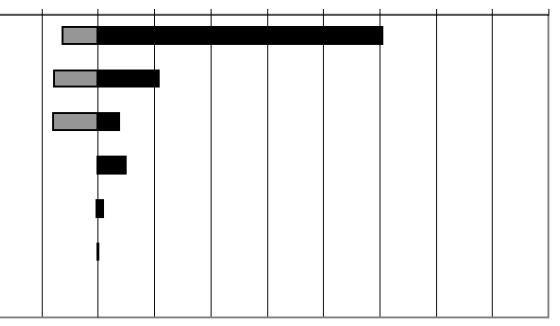

Freshwater eutrophication

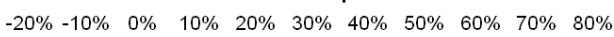

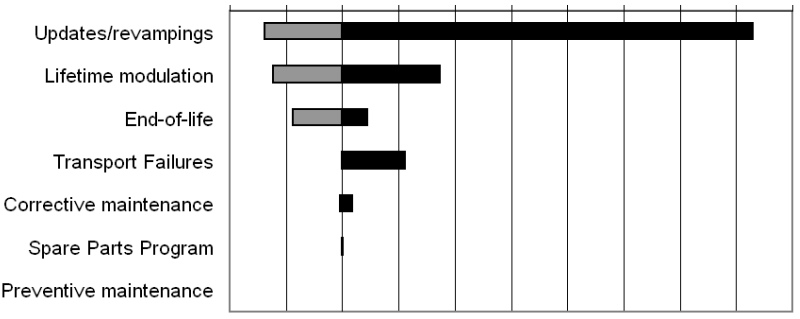

Metal depletion

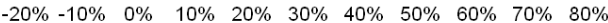

Updates/revampings

Lifetime modulation

End-of-life

Transport Failures

Corrective maintenance

Spare Parts Program

Preventive maintenance

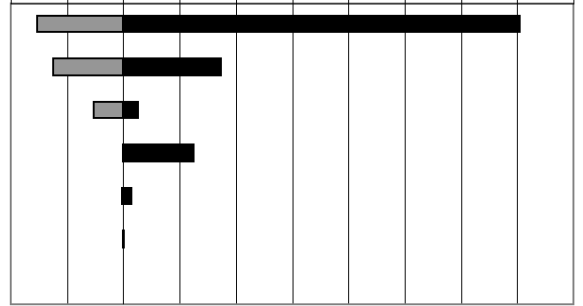

$\square$ Best case $\square$ Worst case

Figure 7. Sensitivity analysis of the relevant parts associated with the best case and worst case scenarios, compared to the baseline scenario taken as a reference and for a hydro energy supply.

\subsection{Proactive and interactive client-oriented use of the model}

Once the model is well implemented in the company, a more proactive and interactive use oriented towards clients may be considered. This process leads to recommendations and good practices to improve the environmental performance of the substation.

In this case the exploitation scenarios of the model are known by the aluminium producer and formalized thanks to a proactive dialog with him. The process is divided into three phases: 
1. The client (the aluminium producer) exploits the substation in a certain way. A scenario of exploitation is built and implemented in the LCA model.

2. A dialog with the aluminium producer identifies the existing degrees of freedom for this scenario. One or several alternative exploitation scenarios are built and implemented.

3. The environmental benefits are measured according to the initial scenario on each impact category. Recommendations are generated by analyzing the significant benefits.

A simple example is proposed to illustrate this process. The aluminium smelter is supplied by hydroelectricity. A dialog with the aluminium producer enables the identification of the initial exploitation scenario that is equivalent to the baseline scenario already used in the previous sections. One particular degree of freedom has been identified concerning the preventive maintenance. Indeed the producer admits that this maintenance may be intensified, and it has been estimated that it would lead to less corrective maintenance, and that the life time of the substation could be lengthened by two years. All these elements have been quantified and implemented in the LCA model. As previously shown, the environmental impacts generated by reinforcing preventive maintenance are negligible compared to the potential impacts to be generated by a corrective maintenance.

The comparison between the two scenarios leads to the environmental benefits presented in Table 2 . For the metal depletion impact category for example, the annual potential impacts are decreased by $18.07 \%$, representing about 216 tons of Fe eq. These quantified results are a powerful driver for the clients to improve their practices.

Used iteratively, they would permit the deployment of a continuous improvement approach centred on eco-design between the supplier and the client. The aim would be to evolve towards more sustainable exploitation scenarios, i.e. scenarios reaching the best compromise between environmental performance and economic requirements. Such a process may be fed by the internal eco-design projects and it may be reiterated in a regular way (every five years for example).

Table 2. Difference of the annual environmental impacts between the initial scenario and the alternative scenario

\begin{tabular}{|l|l|r|r|}
\hline \multicolumn{1}{|c|}{ Impact categories } & \multicolumn{1}{c|}{ Unit } & Difference & Benefits \\
\hline Climate change & $\mathrm{kg} \mathrm{CO} 2 \mathrm{eq}$ & $4.26 \mathrm{E}+04$ & $3.36 \%$ \\
\hline Ozone depletion & $\mathrm{kg} \mathrm{CFC}-11 \mathrm{eq}$ & $1.36 \mathrm{E}-02$ & $11.76 \%$ \\
\hline Human toxicity & $\mathrm{kg} \mathrm{1,4- \textrm {DB } \text { eq }}$ & $2.07 \mathrm{E}+05$ & $17.82 \%$ \\
\hline Particulate matter formation & $\mathrm{kg} \mathrm{PM} 10 \mathrm{eq}$ & $2.37 \mathrm{E}+02$ & $8.62 \%$ \\
\hline Terrestrial acidification & $\mathrm{kg} \mathrm{SO} 2 \mathrm{eq}$ & $3.51 \mathrm{E}+02$ & $9.39 \%$ \\
\hline Freshwater eutrophication & $\mathrm{kg} \mathrm{P} \mathrm{eq}$ & $1.22 \mathrm{E}+02$ & $16.17 \%$ \\
\hline
\end{tabular}




\begin{tabular}{|l|l|r|r|}
\hline Natural land transformation & $\mathrm{m} 2$ & $9.38 \mathrm{E}+00$ & $0.13 \%$ \\
\hline Metal depletion & $\mathrm{kg} \mathrm{Fe}$ eq & $2.16 \mathrm{E}+05$ & $18.07 \%$ \\
\hline
\end{tabular}

\section{Conclusions}

To quickly and accurately assess the environmental performance of complex industrial systems, we have proposed in this paper an LCA model including different exploitation scenarios. The main objective of this approach consists in assessing the potential impacts of generic industrial systems in a more reliable way compared to classical streamlined and upstream LCA, while preserving time and resources. A second interesting perspective concerns the generation of exploitation recommendations to industrial clients in order to optimize the life cycle of the system from an environmental point of view. The exploitation scenarios consider exogenous parameters, i.e. parameters that are not controlled by the supplier of the system. This model is based on a set of external explorative scenarios and the SRI matrix, a simple and intuitive tool. Four scenarios are considered: best case, worst case, baseline (expected future) and a highly different alternative. After identifying relevant parts of the system to be included in the scenarios, values are associated with each parameter and each scenario. The scenarios are implemented in the LCA software and a classical LCA process is performed.

A case study has been proposed concerning an Alstom Grid AC/DC conversion substation used to convert and supply power to aluminium electrolysis plants. We have shown that the consideration of different exploitation scenarios brings accurate and reliable knowledge about the potential environmental impacts generated throughout the life cycle of industrial systems.

However this scenario-based LCA model needs to be manipulated by an LCA expert, or a least by a person familiar with LCA. Future research may consider a more automated and interactive approach through, for example, the generation of a software layer linked with the LCA software and easily manipulable by a non-expert.

Finally another point to improve is the modelling of the electronic parts of the system. These elements are indeed small (compared to the system size) but important parts, and the inventory precision could be improved thanks to the recent ETSI standard (European Telecommunications Standards Institute, 2011).

\section{Acknowledgements}

We would like to thank Frankie Rico-Sanz for his contributions to the applicative steps of this work. We also gratefully thank Joël Devautour and François Puchar from Alstom Grid to their full support in 
this research.

\section{References}

Bishop, P., Hines, A., Collins, T., 2007. The current state of scenario development: an overview of techniques. Foresight 9, 5-25.

Blanchard, B.S., Fabrycky, W.J., 2011. Systems engineering and analysis, Fifth Edition. ed, Prentice Hall International series in industrial and systems engineering. Pearson Prentice Hall, Upper Saddle River N.J., USA.

Börjeson, L., Höjer, M., Dreborg, K.-H., Ekvall, T., Finnveden, G., 2006. Scenario types and techniques: Towards a user's guide. Futures 38, 723-739.

Ciroth, A., 2003. Uncertainty Calculation for LCI Data: Reasons for, against, and an Efficient and Flexible Approach for Doing it, in: Proceedings of the International Workshop on Quality of Life Cycle Inventory (LCI) Data. Karlsruhe, Germany.

Cluzel, F., Yannou, B., Leroy, Y., Millet, D., 2012. Proposition for an Adapted Management Process to Evolve from an Unsupervised Life Cycle Assessment of Complex Industrial Systems Towards an Eco-Designing Organisation. Concurrent Engineering: Research and Applications 20, $111-$ 126.

Dewulf, W., 2003. A pro-active approach to ecodesign: framework and tools (PhD Thesis). Katholieke Universiteit Leuven, Leuven, Belgium, Katholieke Universiteit Leuven, Leuven, Belgium.

European Telecommunications Standards Institute, 2011. ETSI TS 103 199 V1.1.1 (2011-11) Environmental Engineering (EE); Life Cycle Assessment (LCA) of ICT equipment, networks and services; General methodology and common requirements (ETSI Technical Specification). European Telecommunications Standards Institute, Sophia Antipolis, France.

Finnveden, G., Ekvall, T., 1998. Life-cycle assessment as a decision-support tool-the case of recycling versus incineration of paper. Resour Conserv Recy 24, 235-256.

Fukushima, Y., Hirao, M., 2002. A Structured Framework and Language for Scenario-Based Life Cycle Assessment. Int J Life Cycle Ass 7, 317-329.

Hawken, P., Ogilvy, J.A., Schwartz, P., 1982. Seven Tomorrows. Bantam Dell Pub Group.

Höjer, M., Ahlroth, S., Dreborg, K.-H., Ekvall, T., Finnveden, G., Hjelm, O., Hochschorner, E., Nilsson, M., Palm, V., 2008. Scenarios in selected tools for environmental systems analysis. Journal of Cleaner Production 16, 1958-1970.

Huijbregts, M.A.J., 1998. Application of uncertainty and variability in LCA - Part I: A general framework for the analysis of uncertainty and variability in Life Cycle Assessment. Int J Life Cycle Ass 3, 273-280.

Huijbregts, M.A.J., Norris, G., Bretz, R., Ciroth, A., Maurice, B., Bahr, B., Weidema, B., Beaufort, A.S.H., 2001. Framework for modelling data uncertainty in life cycle inventories. Int J Life Cycle Ass 6, 127-132.

Hur, T., Lee, J., Ryu, J., Kwon, E., 2005. Simplified LCA and matrix methods in identifying the environmental aspects of a product system. J Environ Manage 75, 229-237.

International Organization for Standardization (ISO), 2006a. ISO 14044:2006 - Environmental management - Life cycle assessment - Requirements and guidelines.

International Organization for Standardization (ISO), 2006b. ISO 14040:2006 - Environmental management - Life cycle assessment - Principles and framework.

International Organization for Standardization, 2011. ISO 14006:2011 - Environmental management systems - Guidelines for incorporating ecodesign (ISO Standard), Environmental management.

Lane, J., Lant, P., 2012. Including N2O in ozone depletion models for LCA. Int J Life Cycle Assess 17, 252-257.

Leroy, Y., Froelich, D., 2010. Qualitative and quantitative approaches dealing with uncertainty in life cycle assessment (LCA) of complex systems: towards a selective integration of uncertainty according to LCA objectives. Int J Design Eng 3, 151-171.

Liu, G., Müller, D.B., 2012. Addressing sustainability in the aluminum industry: a critical review of life cycle assessments. Journal of Cleaner Production 35, 108-117.

Lloyd, S.M., Ries, R., 2007. Characterizing, Propagating, and Analyzing Uncertainty in Life-Cycle Assessment: A Survey of Quantitative Approaches. J Ind Ecol 11, 161-179.

Millet, D., Bistagnino, L., Lanzavecchia, C., Camous, R., Poldma, T., 2007. Does the potential of the use of LCA match the design team needs? Journal of Cleaner Production 15, 335-346. 
Ostad-Ahmad-Ghorabi, H., Collado-Ruiz, D., 2011. Tool for the environmental assessment of cranes based on parameterization. The International Journal of Life Cycle Assessment 16, 392-400.

Pesonen, H.-L., Ekvall, T., Fleischer, G., Huppes, G., Jahn, C., Klos, Z.S., Rebitzer, G., Sonnemann, G.W., Tintinelli, A., Weidema, B.P., Wenzel, H., 2000. Framework for scenario development in LCA. The International Journal of Life Cycle Assessment 5, 21-30.

Reap, J., Roman, F., Duncan, S., Bras, B., 2008a. A survey of unresolved problems in life cycle assessment - Part 1: goal and scope and inventory analysis. The International Journal of Life Cycle Assessment 13, 290-300.

Reap, J., Roman, F., Duncan, S., Bras, B., 2008b. A survey of unresolved problems in life cycle assessment - Part 2: impact assessment and interpretation. The International Journal of Life Cycle Assessment 13, 374-388.

Ross, S., Evans, D., Webber, M., 2002. How LCA studies deal with uncertainty. Int J Life Cycle Ass 7 , 47-52.

Schmidt, J., Thrane, M., 2009. Life cycle assessment of aluminium production in new Alcoa smelter in Greenland.

Spielmann, M., Scholz, R., Tietje, O., Haan, P. de, 2004. Scenario Modelling in Prospective LCA of Transport Systems. Application of Formative Scenario Analysis. Int J Life Cycle Ass 10, 325335.

Tietje, O., 2005. Identification of a small reliable and efficient set of consistent scenarios. European Journal of Operational Research 162, 418-432.

Wack, P., 1985. Scenarios: shooting the rapids. Harvard Bus Rev 63, 139-150.

Weckenmann, A., Schwan, A., 2001. Environmental life cycle assessment with support of fuzzy-sets. Int J Life Cycle Ass 6, 13-18.

Weidema, B.P., Ekvall, T., Pesonen, H.-L., Rebitzer, G., Sonnemann, G.W., Spielmann, M., 2004. Scenarios In Life-Cycle Assessment. SETAC, Pensacola, USA.

Zamagni, A., Buttol, P., Porta, P.L., Buonamici, R., Masoni, P., Guinée, J., Ekvall, T., 2008. CALCAS WP5-D7: Critical review of current research needs and limitations related to ISO-LCA practice - Annex 2 - Reports of the topics and approaches analyzed ( No. CALCAS WP5-D7 Annex 2), CALCAS (Co-ordination Action for innovation in Life-Cycle Analysis for Sustainability). 